\title{
GERMINAÇÃO DE SEMENTES E CRESCIMENTO INICIAL DE MARACUJAZEIROS IRRIGADOS COM ÁGUA SALINA EM DIFERENTES VOLUMES DE SUBSTRATO'
}

\author{
LOURIVAL FERREIRA CAVALCANTE ${ }^{2}$, JOÃO BATISTA DOS SANTOS ${ }^{3}$, CLODOALDO JÚNIOR OLIVEIRA SANTOS ${ }^{3}$, \\ JOSÉ CRISPINIANO FEITOSA FILHO ${ }^{2}$, ELY MARTINS DE LIMA ${ }^{4}$, ITALO HEBERT LUCENA CAVALCANTE 5
}

\begin{abstract}
RESUMO - No período de novembro de 2000 e fevereiro de 2001, estudaram-se os efeitos da salinidade da água de irrigação aos níveis de 0,5; 1,0; 2,0; 3,0; 4,5 e 6,0 dS m m $^{-1}$ e dos volumes de substrato: 0,34 e 1,41 L sobre a germinação de sementes e algumas variáveis de crescimento inicial em plantas de maracujá-amarelo e roxo (Passiflora edulis f. flavicarpa Deg). Os resultados mostraram que, independentemente da cultivar, apesar de a água salina inibir a germinação e o desenvolvimento das plantas, os efeitos foram mais danosos nos tratamentos com menor volume do substrato. Ambos os genótipos sofreram mais a ação da salinidade durante o crescimento inicial avaliado pela altura, diâmetro do caule, área foliar, crescimento da raiz principal e biomassa das raízes e parte aérea, que por ocasião da germinação das sementes. As mudas irrigadas com águas de condutividade elétrica superior a $1,0 \mathrm{dS} \mathrm{m}{ }^{-1}$ não apresentaram qualidade para plantio.
\end{abstract}

Termos para indexação: Água salina, substrato, produção de mudas, maracujazeiro.

\section{SEED GERMINATION AND INITIAL GROWTH OF PASSION FRUIT PLANTS IRRIGATED WITH SALINE WATER IN SUBSTRACT OF DIFFERENTS VOLUME}

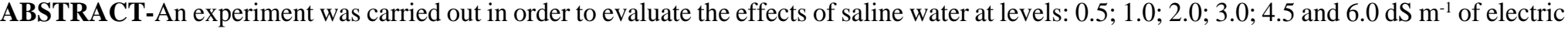
conductivity and the effects of substrate volume of 0.34 and 1.41 liter on seed germination and some variables of initial growth in passion fruit plants ( Passiflora edulis f. flavicarpa Deg) cultivars yellow and purple, during November of 2000 and February of 2001. The data showed that the saline content of the water irrigation inhibited the seed germination process and the initial growth of the passion fruit plants although they have been more drastic in treatment with smaller volumes of substrate. The action of saline water produced an effect more harmful to plants growth than during the seed germination of both genotypes evaluated by height growth, stem diameter, leaf area, primary root growth and dry matter production of roots and area part of the plants. The seedling irrigated with water of electric conductivity higher than $1.0 \mathrm{dS} \mathrm{m}^{-1}$ didn't present agronomic qualities to planting. Index terms: Saline water, substrate, seedling production, passion fruit.
\end{abstract}

\section{INTRODUÇÃO}

A produção de mudas, em geral, das culturas e particularmente das espécies frutíferas tropicais, representa um dos mais importantes pré-requisitos para o sucesso do empreendimento agrícola. Nesse sentido, pelo menos três critérios devem ser adotados para a aquisição de material biológico de boa qualidade: 1) sementes ou outro órgão da planta, homogêneos e fitossanitariamente adequados para reprodução (Ruggiero \& Oliveira, 1998); 2)componentes, composição e volumes do substrato (Silva et al., 2001); 3) qualidade da água para irrigação (Miguel et al., 1998).

Nas áreas semi-áridas do Brasil, a água de irrigação, quase sempre, possui concentração salina que compromete a qualidade de mudas da grande maioria das fruteiras (Cavalcante et al., 2001a). No caso do maracujazeiro, a adversidade revela-se ainda mais agressiva devido à cultura ser sensível à salinidade da água ou do solo (Ayers \& Westcot, 1999). Para os respectivos autores, toda e qualquer planta sensível aos efeitos salinos apresenta perda potencial do seu rendimento quando a concentração de sais do substrato evidenciar condutividade elétrica superior a $1,3 \mathrm{dS} \mathrm{m}^{-1}$.

Os efeitos marginais da salinidade atuam durante todas as fases das plantas (Sá, 1999). No entanto, o primeiro contato entre o ambiente salino e as plântulas tem início durante o crescimento do eixo embrionário da semente. Por isso, o processo germinativo constitui-se na fase mais importante para a avaliação do comportamento de determinada cultura à salinidade (Lauchi \& Epstein, 1984; Costa, 2000). Entretanto, algumas frutíferas, como goiabeira (Pereira, 2000), gravioleira (Cavalcante et al., 2001b) e inclusive o maracujazeiro (Costa, 2000), revelaram-se menos tolerantes aos sais durante o crescimento inicial das plantas que por ocasião da germinação das sementes.

Além da ação química depressiva dos sais, da água ou dos substratos às plantas, há também os efeitos negativos da salinidade sobre a condição física do solo. As interferências do complexo que representam a mistura salina e/ou da ação específica de boro, cloreto, nitrato e sódio tornam-se mais danosas quando os sais induzem a dispersão da argila e depauperam a estrutura do solo (Richards, 1954; Costa, 2000). Quando isso ocorre, os atributos físico-hídricos do meio, como infiltração, disponibilidade de água, aeração e drenagem são marcadamente reduzidos e o $\mathrm{pH}$ é sensivelmente elevado. Nessas situações, na maioria dos casos, não há espaço, com condições químicas, físicas e biológicas, para o desenvolvimento do sistema radicular e, com efeito, para o crescimento inicial das plantas em substratos de pequenos volumes (Santos, 1999).

A utilização da água salina na agricultura, isto é, acima de 1,5 $\mathrm{dS} \mathrm{m}{ }^{-1}$, que contém $0,96 \mathrm{~g}$ de sais por litro, está tornando-se cada vez mais necessária (Paz et al., 2000). Contudo, a literatura constata que a água de conteúdo salino acima desse valor tem comprometido a produção de mudas de goiabeira, gravioleira, mamoeiro, maracujazeiro e pinheira, todas de significativa importância para a região semi-árida do Brasil. Grandes perdas de mudas também têm sido registradas em áreas onde a água de mananciais de superfície (açudes, barragens e rios) tem a concentração salina aumentada, do início para o final da estiagem, provocando toxidez e até a morte das plantas.

O trabalho objetivou avaliar os efeitos da água salina, em volumes de substrato, sobre a germinação de sementes e crescimento inicial do maracujazeiro-amarelo e roxo.

\section{MATERIALEMÉTODOS}

O trabalho foi conduzido em abrigo protegido do Departamento de Fitotecnia/CCA/UFPB, no período de novembro de 2000 a fevereiro de 2001. Os tratamentos foram distribuídos em blocos inteiramente casualizados, em 5 repetições, sendo as paracelas constituídas por 15 unidades experimentais de cada genótipo, empregando o esquema fatorial

\footnotetext{
1 (Trabalho 016/2002). Recebido: 22/02/2002. Aceito para publicação: 10/10/2002.

Parte do trabalho de conclusão de Curso do segundo autor.

2 Prof. do DSER/CCA/UFPB, Areia-PB. Bolsista do CNPq. Fone: (0xx83) 362-2300. lofeca@ cca.ufpb.br

3 Engo Agro e MSc em Manejo de Solo e Água, CCA/UFPB, Areia-PB.Fone: (0xx83) 381-1145. agrosantos@bol.com.br

4 Engo Agro MSc em Fruticultura Tropical e Irrigação - EMATER - Paraíba, Areia-PB. Fone: (0xx83) 362-2355.

5Aluno de Agronomia, CCA/UFPB, Bolsista PIBIC/CNPq. Areia-PB. Fone: (0xx83) 244-7351. Italohlc@ zipmail.com.br
} 
$2^{2} \times 6$, correspondente às cultivares de maracujazeiro-amarelo e roxo (Passiflora edulis f. flavicarpa Deg.), submetidas a dois volumes de substrato: 0,34 e 1,41 litro, irrigados com águas com salinidades de: 0,5 ; 1,$0 ; 2,0 ; 3,0 ; 4,5$ e $6,0 \mathrm{dS} \mathrm{m}^{-1}$ de condutividade elétrica (CE).

Os respectivos níveis de salinidade (CE) foram obtidos mediante a diluição de uma água oriunda de uma barragem altamente salina com condutividade elétrica de $16,9 \mathrm{dS} \mathrm{m}^{-1}$ e relação de adsorção de sódio (RAS) de 17,8 $\left(\mathrm{mmol} \mathrm{L}^{-1}\right)^{1 / 2}$, com água não salina de $\mathrm{CE}=0,5 \mathrm{dS} \mathrm{m}^{-}$ ${ }^{1}$. A diluição foi feita tomando-se um volume constante da água salina com volumes de água sem problemas de sais e medindo-se a condutividade elétrica para cada tratamento, conforme procedeu Pereira (2000).

O substrato, sem calcário e fertilizante, foi composto de volumes iguais de areia lavada, material da camada superficial $(10 \mathrm{~cm})$ de um Latossolo Vermelho-Amarelo e esterco bovino de relação C/N de 12:1, acondicionado em bolsas de polietileno preto com $18 \times 10 \mathrm{~cm}$ e $12 \times 6 \mathrm{~cm}$, correspondentes aos volumes de 1,41 e 0,34 litro, respectivamente. Imediatamente após preparado, o substrato apresentava caráter salino devido, em maior parte, à solubilização dos componentes da matéria orgânica: cálcio $=15,8 ;$ magnésio $=12,4 ;$ sódio $=36,7$; e potássio $=2,0 \mathrm{mmol}$ $\mathrm{L}^{-1}$ e condutividade elétrica do extrato de saturação $6,9 \mathrm{dS} \mathrm{m}^{-1}$, determinados no extrato de saturação, empregando a metodologia de Richards (1954). Para reduzir o índice de salinidade, cada unidade experimental foi irrigada semanalmente com água não salina de $\mathrm{CE}=0,5 \mathrm{dS} \mathrm{m}^{-1}$ e RAS = $2,2\left(\mathrm{mmol}_{\mathrm{c}} \mathrm{L}^{-1}\right)^{1 / 2}$. Ao final de 45 dias, após uma lavagem para lixiviação dos sais, o substrato continha condutividade elétrica do extrato de saturação de $1,8 \mathrm{dS} \mathrm{m}^{-1} \mathrm{e}$, portanto, apresentava conteúdo não salino .

No início da segunda quinzena de novembro de 2000 , foi efetivada a semeadura de 8 sementes de cada cultivar com $87 \%$ de germinação para o maracujazeiro-amarelo e $81 \%$ relativo ao roxo. Os respectivos valores foram obtidos com base em plântulas normais emergidas conforme metodologia adotada pelas Regras de Análises de Sementes descritas em Brasil (1992). Antes da semeadura, o substrato apresentava porosidade total de $0,62 \mathrm{~m}^{3} \mathrm{~m}^{-3} \mathrm{e}$ a umidade volumétrica ao nível de capacidade de campo à tensão de $-0,010 \mathrm{MPa}$ de $0,22 \mathrm{~m}^{3} \mathrm{~m}^{-3}$ (Richards, 1954).

Antes de iniciar a irrigação, as unidades experimentais foram pesadas e acrescentadas à massa de água referente ao valor do substrato ao nível de capacidade de campo. Esse valor foi adotado como padrão para as irrigações seguintes. $\mathrm{O}$ fornecimento de água, referente a cada nível de salinidade, foi feito com base na pesagem das respectivas unidades experimentais, repondo-se diariamente a água evaporada em relação ao peso-padrão no dia da semeadura, tomando-se o cuidado para não molhar o caule e as folhas e não induzir a toxidade pelo contato com as águas mais salinizadas.

No período de 29 de novembro a 11 de dezembro de 2000, foram contadas as sementes germinadas. Ao final do processo germinativo, o número de sementes germinadas foi dividido por 8 e multiplicado por $87 \%$, as referentes cultivares amarelas e por $81 \%$ à roxo (Brasil, 1992). Aos 10 dias após a emergência, foi efetivado o desbaste mantendo-se a planta mais vigorosa de cada unidade experimental.

Aos oitenta dias após a emergência, isto é, ao final do ensaio, foram obtidos os valores de crescimento em altura, diâmetro do caule à altura do colo das plantas, com auxílio de um paquímetro de precisão 1:50, área foliar estimada pelo produto do comprimento pela maior largura da folha. O material vegetal de cada repetição foi separado para quantificação dos pesos das matérias secas da parte aérea e do sistema radicular. Posteriormente, o substrato foi colocado numa bandeja com malha fina, umedecido paulatinamente até a saturação para liberação das raízes. Em seguida, mediu-se o comprimento da raiz principal com auxílio de uma régua milimetrada.

A correção da área foliar foi feita, efetuando-se o produto da área estimada pelo fator 0,78 para a cultivar amarela e 0,81 para a roxa. Cada um dos fatores correspondeu à relação entre os pesos do papel referente à área real e à área estimada de cada genótipo (Santos, 1999).

Os dados foram submetidos à análise de variância, pelo teste
"F", confronto de médias, pelo teste de Tukey, e regressão polinomial. Para efeitos de regressão, foram utilizados os intervalos salinidade da água versus volume de substrato, devido à maioria das variáveis não diferirem entre as cultivares.

\section{RESULTADOSE DISCUSSÃO}

A salinidade da água de irrigação prejudicou mais significativamente a germinação de sementes e o crescimento do maracujazeiroroxo que do amarelo (Tabela 1). Essa situação mostra que genótipos de uma mesma espécie podem responder diferenciadamente à ação da salinidade da água e do substrato durante a germinação de sementes e o crescimento inicial das plantas (Richards, 1954; Ayers \& Westcot, 1999; Pereira, 2000). Por outro lado, verifica-se que, comparativamente, pelo diâmetro do caule, área foliar, comprimento da raiz principal e produção de matéria seca das raízes e parte aérea (Tabela 1), as plantas de ambas as cultivares responderam sem diferença estatística aos efeitos da salinidade.

$\mathrm{O}$ aumento da condutividade elétrica das águas, independentemente da cultivar, interferiu negativamente sobre o poder germinativo das sementes e as demais variáveis de crescimento das plantas (Tabela 1). No entanto, os menores valores foram sempre registrados no substrato em menor volume (Tabela 1, Figuras 1 e 2). Nessa condição, o estresse salino tornou-se mais danoso às sementes e às plantas. A redução do volume, do menor recipiente, para menos de $25 \%$ de 1,41 litro além do estresse de sais resultou em impedimento à expansão radicular e, em conseqüência, ao desenvolvimento adequado das plantas (Santos, 1999). Pelos resultados deste trabalho nas áreas onde as águas apresentarem condutividade elétrica igual e/ou superior a 1,0 dS $\mathrm{m}^{-1}$ ou que possam atingir esse valor do meio para o final do período de estiagem, a produção de mudas de maracujazeiro em recipientes de volumes inferiores a 1,41 litro pode ser expressivamente comprometida. Essas inconveniências foram também registradas por Cavalcante et al. (2001a) ao estudarem a possibilidade do uso da água salina no cultivo do maracujazeiro.

O diâmetro do caule das plantas foi negativamente afetado, pelo incremento salino da água, com maior intensidade nos tratamentos com menor volume do substrato (Tabela 1, Figura 3). O contato das raízes com o meio adversamente salino contribui para maior e mais rápida absorção de sais que provocam depressividade a todos os órgãos das plantas, inclusive ao caule (Araújo et al., 2000).

Independentemente da cultivar, a diminuição do volume do substrato e o aumento da salinidade da água de irrigação resultaram em declínio marcante da área foliar, com maior significância às plantas desenvolvidas no substrato de menor volume (Tabela 1, Figura 4). A redução da área foliar, muitas vezes, é reflexo de estresse no ambiente radicular e pode provocar desequilíbrio fisiológico nas plantas em geral (Lauchi \& Epstein, 1984; Ayers \& Westcot, 1999). Como na maioria das plantas cultivadas, no maracujazeiro, a queda dos valores de expansão das folhas resulta em baixa eficiência fotossintética, desequilíbrio na absorção e translocação de nutrientes, prejuízos à dinâmica de funcionamento dos estômatos e na síntese de auxinas para o crescimento, retardamento na emissão dos botões florais e, com efeito, queda na qualidade fitotécnica das mudas (Costa, 2000).

$\mathrm{O}$ crescimento da raiz principal apresentou o mesmo comportamento estatístico das demais variáveis entre as distintas cultivares nos respectivos recipientes. Entretanto, com o incremento de sais nas águas, houve maior redução desse parâmetro em condições de menor volume de substrato (Figura 5). Ao admitir que todas as variáveis foram estatisticamente inferiores (Tabela 1) no substrato de menor volume, constata-se que as águas de mesmo índice salino são potencialmente mais danosas em condições de menor espaço destinado ao crescimento radicular (Richards, 1954; Sá, 1999; Cavalcante et al., 2001b).

As produções de matéria seca pelas raízes e parte aérea das plantas também foram estatisticamente diminuídas com o aumento da concentração salina das águas e com a redução do volume do substrato 
(Tabela 1, Figuras 6 e 7). Comparativamente, os resultados do maracujazeiro-amarelo foram superiores aos apresentados por Sá (1999) em plantas irrigadas com água salina e inferiores aos de Araújo et al. (2000) por plantas de mesma idade tratadas com água não salina.

Numa avaliação global, verifica-se que o crescimento em altura, diâmetro do caule, comprimento da raiz principal, área foliar e produção de matéria seca das raízes e parte aérea das plantas foram mais drasticamente afetados que a germinação das sementes. Esse fato indica que, apesar de a cultura ser sensível aos efeitos salinos (Ayers \& Westcot, 1999), a sua sensibilidade aos sais é maior na fase de formação das mudas quando comparada à germinação das sementes.

TABELA 1 - Valores de germinação de sementes (G), altura de plantas (AP), diâmetro do caule (DC), área foliar (AF), comprimento da raiz principal (CRP), peso de matéria seca das raízes (MSR) e peso da matéria seca da parte aérea (MPA) das plantas de maracujá, em função da salinidade da água e volume do substrato.

\begin{tabular}{|c|c|c|c|c|c|c|c|}
\hline \multicolumn{2}{|l|}{ Fonte } & $\mathrm{G}^{*}$ & $\mathrm{AP}$ & $\mathrm{DC}$ & $\mathrm{AF}$ & CRP & MSR MPA \\
\hline - & & $\%$ & cm planta $^{-1}$ & mm planta $^{-1}$ & $\mathrm{~cm}^{2}$ planta ${ }^{-1}$ & $\mathrm{~cm}$ planta $^{-1}$ & ---g planta ${ }^{-1}---$ \\
\hline Cultivar & $C_{1}$ & $57,64 a$ & $18,0 \mathrm{a}$ & $2,21 a$ & $51,87 a$ & $8,27 a$ & $0,31 a \quad 1,77 a$ \\
\hline & $\mathrm{C}_{2}$ & $50,32 b$ & $15,2 b$ & $2,16 \mathrm{a}$ & $45,72 a$ & $8,16 a$ & $0,28 \mathrm{a} \quad 1,56 \mathrm{a}$ \\
\hline $\mathrm{dms}$ & & 3,67 & 2,74 & 0,19 & 6,44 & 1,44 & 0,49 \\
\hline Volume de & $V_{1}$ & $58,84 a$ & $19,3 \mathrm{a}$ & $2,51 a$ & $59,78 \mathrm{a}$ & $10,26 \mathrm{a}$ & $0,33 \mathrm{a} \quad 2,07 \mathrm{a}$ \\
\hline substrato & $V_{2}$ & $49,18 b$ & 14,06 & $1,81 b$ & $37,81 \mathrm{~b}$ & 6,676 & $0,26 \mathrm{~b} \quad 1,26 \mathrm{~b}$ \\
\hline dms & & 9,38 & 2,74 & 0,19 & 6,44 & 1,44 & 0,49 \\
\hline & $0,5 \mathrm{dS} \mathrm{n}$ & $61,21 a$ & $28,4 a$ & $2,83 a$ & $59,99 \mathrm{a}$ & $15,58 \mathrm{a}$ & $0,45 \mathrm{a} \quad 2,92 \mathrm{a}$ \\
\hline Nível de & $1,0 \mathrm{dS} \mathrm{m} \mathrm{m}^{-1}$ & $56,11 \mathrm{ab}$ & $19,6 b$ & $2,50 \mathrm{ab}$ & $59,02 \mathrm{a}$ & $8,94 b$ & $0,42 a \quad 2,72 a$ \\
\hline salinidade & $2,0 \mathrm{dS} \mathrm{m}$ & $53,37 \mathrm{bc}$ & $18,1 b c$ & $2,26 b c$ & $55,49 a b$ & $7,95 b$ & $0,31 a b \quad 1,88 a b$ \\
\hline da água & $3,0 \mathrm{dS} \mathrm{m}^{-1}$ & $52,51 b c$ & $12,5 \mathrm{~cd}$ & $1,98 \mathrm{~cd}$ & $42,34 b c$ & $7,63 \mathrm{~b}$ & $0,22 b \quad 1,06 b$ \\
\hline & $4,5 \mathrm{dS} \mathrm{m}^{-1}$ & $52,47 \mathrm{bc}$ & $10,8 d$ & $1,78 \mathrm{~cd}$ & $40,29 b c$ & $5,43 b$ & $0,19 b \quad 0,74 b$ \\
\hline & $6,0 \mathrm{dS} \mathrm{m}^{-1}$ & $48,82 \mathrm{c}$ & $10,3 \mathrm{~d}$ & $1,76 \mathrm{~d}$ & $35,52 \mathrm{c}$ & $7,04 b$ & $0,17 b \quad 0,68 b$ \\
\hline $\mathrm{dms}$ & & 6,38 & 7,01 & 0,49 & 16,45 & 3,70 & 0,17 \\
\hline
\end{tabular}

* Dados transformados para arc-sen $\sqrt{\mathrm{x}} ; \mathrm{C}_{1}$ e $\mathrm{C}_{2}=$ cultivares amarelo e roxo; $\mathrm{V}$ $=1,41 \mathrm{~L} ; \mathrm{V}_{2}=0,34 \mathrm{~L} ; \mathrm{dms}=$ diferença mínima significativa; médias seguidas de mesma letra minúscula nas colunas não diferem entre si, pelo teste de Tukey, para $\mathrm{p}<0,05$.

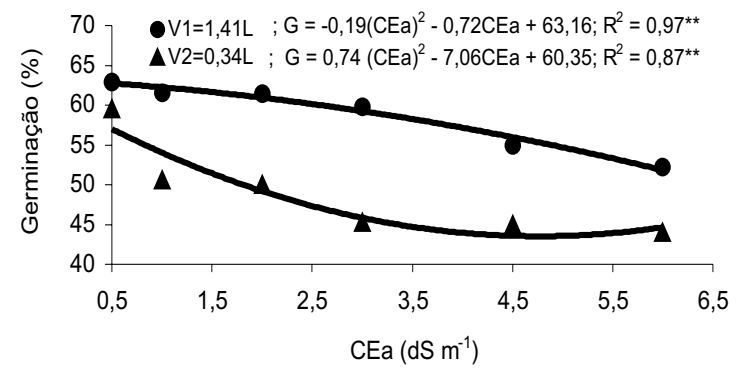

FIGURA 1 - Valores médios de germinação de sementes (G) de maracujazeiro-amarelo e roxo em função da salinidade da água e volume do substrato.

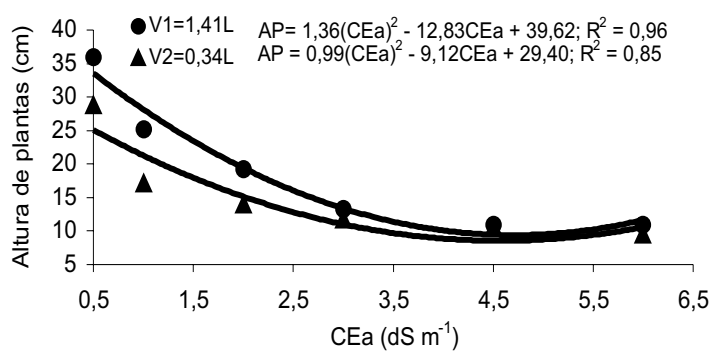

FIGURA 2 - Crescimento médio em altura de plantas (AP) de maracujazeiro-amarelo e roxo em função da salinidade da água e volume do substrato.

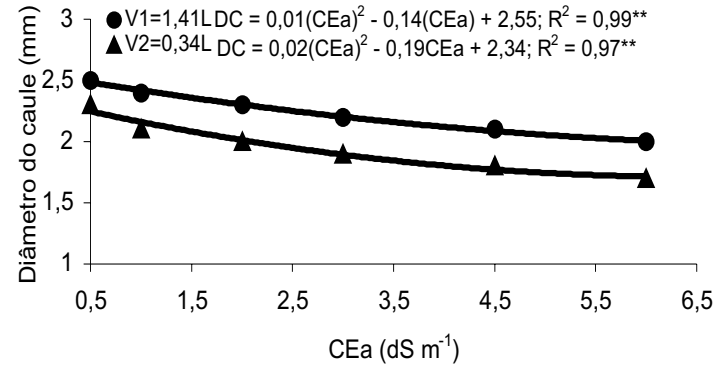

FIGURA 3 - Diâmetro médio do caule (DC) de plantas de maracujazeiroamarelo e roxo em função da salinidade da água e volume do substrato.

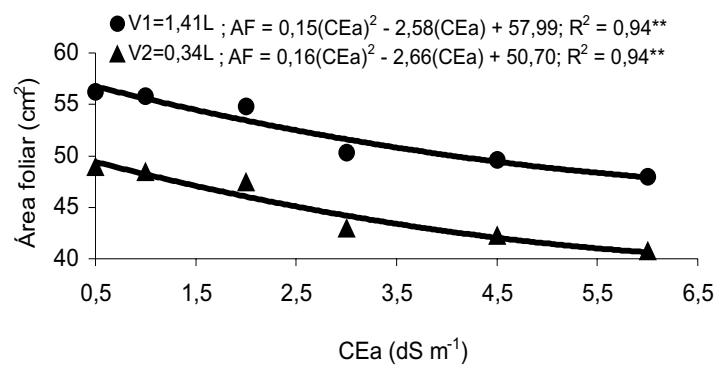

FIGURA 4 - Área foliar média (AF) de plantas de maracujazeiro- amarelo e roxo em função da salinidade da água e volume do substrato.

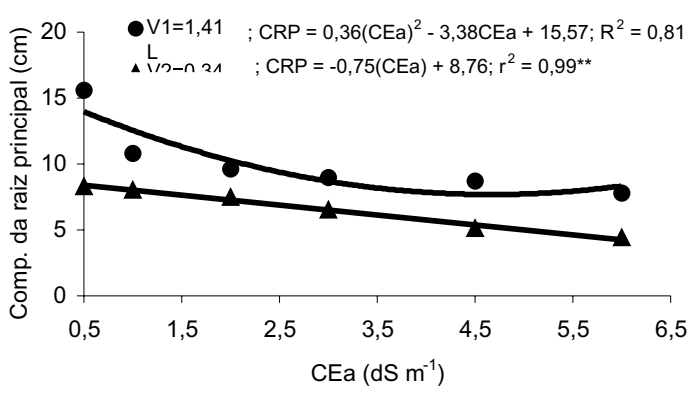

FIGURA 5 - Comprimento médio da raiz principal (CRP) de plantas de maracujazeiro-amarelo e roxo em função da salinidade da água e volume do substrato.

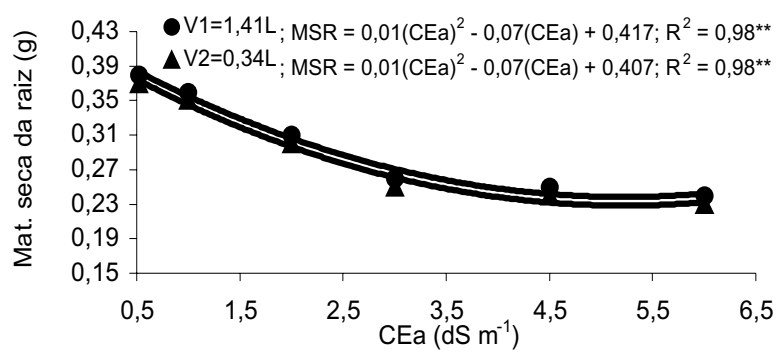

FIGURA 6 - Valores médios de matéria seca das raízes (MSR) de plantas de maracujazeiro-amarelo e roxo em função da salinidade da água e volume do substrato.

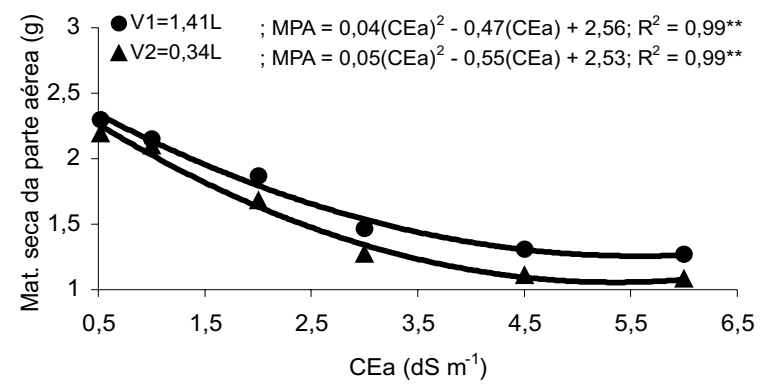

FIGURA 7 - Valore médios de matéria seca da parte aérea (MPA) de plantas de maracujazeiro-amarelo e roxo em função da salinidade da água e volume do substrato. 


\section{CONCLUSÕES}

1. A salinidade da água diminuiu a taxa de germinação das sementes, o crescimento e desenvolvimento das cultivares de maracujazeiro.

2. Os menores valores de germinação das sementes, do crescimento em altura, do diâmetro do caule, área foliar, comprimento da raiz principal, produção de matéria seca das raízes e parte aérea das plantas, provocados pela salinidade das águas, foram registrados no substrato de menor volume.

3. Os efeitos da salinidade foram mais agressivos sobre crescimento em altura, diâmetro do caule, área foliar e biomassa das plantas que na germinação das sementes.

4. Não foram produzidas mudas com qualidade para cultivo quando irrigadas com águas de salinidade superior a $1,0 \mathrm{dSm}^{-1}$.

\section{REFERÊNCIASBIBLIOGRÁFICAS}

ARAÚJO, D. da C.; SÁ, J. R. de LIMA, E. M. de .; et al. Efeito do volume de água e da cobertura morta sobre o crescimento inicial do maracujazeiro-amarelo. Revista Brasileira de Engenharia Agrícola e Ambiental, Campina Grande, v. 4, n.1, p. 121 - 124. 2000.

AYERS, R. S.; WESTCOT. D.W. A qualidade de água na agricultura. Campina Grande: Universidade Federal da Paraíba, 1999. p. 1-53. (FAO Irrigation Drainage Daper, 29)

CAVALCANTE, L. F.; CARVALHO, S. S. de.;LIMA, E. M. de.; et al. Desenvolvimento inicial da gravioleira sob fontes e níveis de salinidade da água. Revista Brasileira de Fruticultura, Jaboticabal, v. 23, n.2, p.445-459. 2001b.

BRASIL. Ministério da Agricultura. Departamento Nacional de Produção Vegetal. Divisão de Sementes e Mudas. Regras para Análise de Sementes. Brasília, 1992.

CAVALCANTE, L. F.; LIMA, E. M. de.; CAVALCANTE, I. H. L. Possibilidade do uso de água salina no cultivo do maracujazeiro-amarelo. Areia: Editorações Gráficas Diniz, 2001a. 42p.

COSTA, J. R. M. Efeito do revestimento lateral das covas e volumes de água salina sobre a produção e qualidade de frutos do maracujazei- ro-amarelo. 2000. 72f. Dissertação (Mestrado em Produção Vegetal) - Centro de Ciências Agrárias, Universidade Federal da Paraíba, Areia, 2000.

LAUCHI, A.; EPSTEIN, E. Mechanism of salt tolerance for plants. California Agriculture, Oakland, v. 38, n.10, p.12-20. 1984.

MIGUEL, A. A.; ALVES, G. da S.; SÁ, J. R. DE; et al. Influência da salinidade da água de irrigação e do substrato sobre a germinação de sementes e crescimento inicial do maracujazeiro-amarelo. Anais do CPG em Manejo de Solo e Água, Areia, v.20, p.32 - 39. 1998.

PAZ, V. P. da S.; TEODORO, R. E. F.; MENDONÇA, F. C. Recursos hídricos, agricultura irrigada e meio ambiente. Revista Brasileira de Engenharia Agrícola e Ambiental, Campina Grande, v.4, n.3, p.465 475. 2000.

PEREIRA, K. S. N. Tolerância variável da goiabeira à salinidade da água de irrigação durante a germinação de sementes e produção de mudas. 2000. 82f. Dissertação (Mestrado em Manejo de Solo e Água). Centro de Ciências Agrárias, Universidade Federal da Paraíba, Areia, 2000.

RICHARDS, L. A. Diagnostico y recuperación de suelos salinos y sódicos. México, 1954. 172p. (Manual de Agricultura, 60).

RUGGIERO, C; OLIVEIRA, J. C. Enxertia do maracujazeiro. In: Ruggiero, C. (editor). Maracujá do plantio à colheita. Jaboticabal: FCAV/SBF, 1998. p.70-92.

SÁ. J. R. de. Níveis de salinidade da água sobre o comportamento do maracujazeiro-amarelo (Passiflora edulis f. flavicarpa Deg.) cultivado em recipientes de polietileno. 1999. 53f. Monografia (Trabalho de Graduação em Agronomia) - Centro de Ciências Agrárias, Universidade Federal da Paraíba, Areia, 1999.

SANTOS, J. B. dos. Produção e qualidade de mudas de maracujazeiroamarelo irrigado com água salina. 1999. 57p. Monografia. (Trabalho de Graduação em Agronomia) - Centro de Ciências Agrárias, Universidade Federal da Paraíba, Areia, 1999.

SILVA, R. P. DA.; PEIXOTO, J.R.; JUNQUEIRA, N. T. V. Influência de diversos substratos no desenvolvimento de mudas de maracujáazedo (Passiflora edulis Sims f. flavicarpa Deg.) Revista Brasileira de Fruticultura, Cruz das Almas, v.23, n.2, p.337-381. 2001. 